\title{
Erratum zu: Die Entwicklung bayerischer Hochschulrechenzentren - Handlungsempfehlungen aus einer Fallstudie für ein professionelles IT-Servicemanagement
}

\author{
Claudius Jonas $(\mathbb{D} \cdot$ Jonathan Lautenschlager $(\mathbb{D} \cdot$ Torsten Eymann
}

Angenommen: 10. August 2021 / Online publiziert: 31. August 2021

(C) Der/die Autor(en) 2021

\section{Erratum zu:}

\section{HMD 2021}

https://doi.org/10.1365/s40702-021-00763-7

In diesem Artikel wurde der englische Titel falsch angegeben als:

German Rectors' Conference (2018) Information Security as a Strategic Task for Leaders of Universities

Der korrekte englische Titel lautet:

The Development of Bavarian University Computer Centres-Recommendations for Action from a Case Study for Professional IT Service Management

Funding Open Access funding enabled and organized by Projekt DEAL.

Open Access Dieser Artikel wird unter der Creative Commons Namensnennung 4.0 International Lizenz veröffentlicht, welche die Nutzung, Vervielfältigung, Bearbeitung, Verbreitung und Wiedergabe in jeglichem Medium und Format erlaubt, sofern Sie den/die ursprünglichen Autor(en) und die Quelle ordnungsgemäß nennen, einen Link zur Creative Commons Lizenz beifügen und angeben, ob Änderungen vorgenommen wurden.

Die in diesem Artikel enthaltenen Bilder und sonstiges Drittmaterial unterliegen ebenfalls der genannten Creative Commons Lizenz, sofern sich aus der Abbildungslegende nichts anderes ergibt. Sofern das betreffende Material nicht unter der genannten Creative Commons Lizenz steht und die betreffende Handlung

Die Online-Version des Originalartikels ist unter https://doi.org/10.1365/s40702-021-00763-7 zu finden.

Claudius Jonas $(\bowtie) \cdot$ Jonathan Lautenschlager $\cdot$ Torsten Eymann

Projektgruppe Wirtschaftsinformatik des Fraunhofer FIT, Kernkompetenzzentrum Finanz- \& Informationsmanagement, Universität Bayreuth, Universitätsstraße 30, 95447 Bayreuth, Deutschland E-Mail: claudius.jonas@uni-bayreuth.de 
nicht nach gesetzlichen Vorschriften erlaubt ist, ist für die oben aufgeführten Weiterverwendungen des Materials die Einwilligung des jeweiligen Rechteinhabers einzuholen.

Weitere Details zur Lizenz entnehmen Sie bitte der Lizenzinformation auf http://creativecommons.org/ licenses/by/4.0/deed.de. 